\title{
Stability of external and internal implant connections after a fatigue test
}

\author{
Paulo Cesar Pinheiro Feitosa ${ }^{1}$, Ana Paula Barbosa de Lima ${ }^{1}$, Laís Regiane Silva-Concílioํㅡ, \\ William Cunha Brandt ${ }^{2}$, Ana Christina Claro Neves ${ }^{1}$
}

Correspondence: Dr. William Cunha Brandt

'Department of Prosthodontics, Dentistry School, University of Taubate, Taubate-SP, Brazil, 2Department of Dentistry, Area of Implantology,

Email: williamcbrandt@yahoo.com.br University of Santo Amaro, São Paulo-SP, Brazil

\section{ABSTRACT}

Objective: The objective of this study was to compare the torque and detorque values of screw intermediates of external hexagon, internal hexagon, and Morse taper implants in single restorations before and after mechanical cycling. Materials and Methods: The study sample was divided into three groups $(n=10)$ as follows: group EH - external hexagon implant, group IH - internal hexagon implant, and group MT - Morse taper implant. Universal abutments were screwed on the implants, and metal crowns were cemented onto the abutment. The samples were submitted to a mechanical testing of 1 million cycles, with a frequency of 8 cycles per second under a $400 \mathrm{~N}$ load. The application and registration of the screw torque (T0) and detorque (T1) values of the intermediate were performed before and after the test. The results were statistically evaluated by analysis of variance (ANOVA) and Tukey's test $(\alpha=0.05)$. Results: There was no difference between the values of $\mathrm{T} 0$ and $\mathrm{T} 1$ in the intra-group samples. However, the inter-group difference in T0 between the $\mathrm{EH}(12.8 \mathrm{~N} \mathrm{~cm})$ and MT $(18.6 \mathrm{~N} \mathrm{~cm})$ groups and in T1 between the EH $(10.4 \mathrm{~N} \mathrm{~cm})$ and IH $(13.8 \mathrm{~N} \mathrm{~cm})$, EH and MT $(19.4 \mathrm{~N} \mathrm{~cm})$, and MT and IH $(P=0.001)$ groups were significant. The MT group showed a lower variation of T0 and T1. Conclusion: The internal implants, particularly MT, showed better stability in these cases when used for single restorations.

Key words: Dental implant, dental prosthesis, dental prosthesis retention, fatigue

\section{INTRODUCTION}

Dental rehabilitation via implant support has become a routine procedure. In many cases, this is the first option for dentists who are deliberating treatment plans. Implants are an alternative not only for the treatment of total edentulism but also for the replacement of one or more dental elements. ${ }^{[1]}$ The careful consideration of technical parameters and biomechanical parameters, in addition to aesthetic requirements, is imperative. ${ }^{[2]}$

Several studies have been conducted with the goal of achieving an accurate and stable connection between the components of implant systems. ${ }^{[1-6]}$ The connection is achieved by means of bolts created by the union between the implant and the prosthetic component. ${ }^{[1,-5]}$
The most frequently observed complication of screwed and cemented prostheses is loosening of the screw that leads to a misfit of the abutment to the implant after the prosthesis is in use. ${ }^{[1,3-6]}$ The combination of horizontal and vertical misfits may result in a gap leading to an increased area of bacterial accumulation, which complicates clean-up ${ }^{[7,8]}$ and causes gingival inflammation due to the development of microflora in the gap region. Peri-implantitis and subsequent risks of bone resorption as well as posterior fracture of the screw can develop. ${ }^{[9]}$

The screw torque determines the preload. The tensile strength is the initial reaction that generates a compressive force between the components of the prosthesis, which keeps them set together. ${ }^{[2]}$ In addition to the preload, another fundamentally

\footnotetext{
How to cite this article: Feitosa PP, de Lima AB, Silva-Concílio LR, Brandt WC, Claro Neves AC. Stability of external and internal implant connections after a fatigue test. Eur J Dent 2013;7:267-71.

Copyright @ 2013 Dental Investigations Society. DOI: $10.4103 / 1305-7456.115407$
} 
important factor determining the stability of the implant/prosthesis complex is the conical geometric configuration of the connection between the implant and the prosthetic components of internal and external hexagon connection systems..$^{[1,3]}$

In view of the fact that one of the factors of successful maintenance of the prosthesis on the implant is the stability of single restoration screw implants, which tend to become loose after some time of use, the aim of this study was to verify, before and after a fatigue test (cyclic mechanical testing), the detorque value of the different geometric configurations of the internal hexagon, external hexagon, and Morse taper implants with simulation of a year of function.

The hypothesis of this study is that mechanical cycling and geometry of dental implants can interfere with the detorque values and Morse taper connection presents less variation between the initial and final torque.

\section{MATERIALS AND METHODS}

A total of 30 implants (of $4.3 \mathrm{~mm}$ diameter $\times 13 \mathrm{~mm}$ length) and prosthetic components (Neodent, Curitiba, Parana, Brazil) were distributed into three groups: Group EH (external hexagon) - Alvim $\mathrm{Ti}$, group IH (internal hexagon) - Alvim II Plus, and group MT (Morse taper) - CM Alvim. The dental implants were included in an epoxy resin-glass fiber composite (NEMA Grade G-10 rod, Piedmont Plastics, Charlotte, NC, USA) using a parallelometer (Bioart, St. Charles, SP, Brazil), which ensures that the implants are parallel to each other ${ }^{[10]}$ and standardize the incidence of loading cyclic during fatigue test that was subsequently performed. This embedded material has an appropriate elastic modulus (approximately $20 \mathrm{GPa}$ ) similar to bone; ${ }^{[11]}$ it is easily machined and is sufficiently tough to allow cyclic testing.

To construct the coronal part, prefabricated abutments were used. For the EH and IH groups, a universal abutment anti-rotational (Tilite) with a diameter of $4.3 \mathrm{~mm}$ and a titanium screw (Neotorque, Neodent, Curitiba, Brazil) were used. For the MT group, the abutment, $4.3 \mathrm{~mm}$ in diameter, was first attached to a cemented component burnout. They were then fixed onto the implants with a manual key and fixed onto the same standardized waxed crowns, fabricated using a matrix of silicon (Poly 1 N, Polisil, São Paulo, Brazil) for each connection type, representing right mandibular second premolar. The wax maintained access to the screw so that the torque could be recorded after the test even after the prostheses were cemented. For the casting of the crowns, Tilite alloy, composed of nickel, chromium, and titanium, was used (Talladium, Curitiba, PR, Brazil), and the casting process using lost wax (under flame) was performed according to the manufacturer's recommendations.

The access to the screw holes, the abutment, and the crown was protected with polyvinylsiloxane (Adsil/Vigodent, Rio de Janeiro, Brazil) during cementing of the crowns. For this procedure, zinc phosphate cement (SS White, Rio de Janeiro, Brazil) was used according to the specifications of the manufacturer; the crowns were cemented one by one by a single operator; they were kept in the lathevise (SomarAdd, Sao Paulo, SP, Brazil) for $10 \mathrm{~min}$ under finger pressure. Regarding the cementation technique, the literature shows that not only the pressure used but also whether it is static or dynamic may interfere with the thickness of the film. ${ }^{[12]}$

For the application of a torque, the samples were firmly fixed on a bench (Somar, São Paulo, Brazil). Initially, two torques of the same value $(20 \mathrm{~N} \mathrm{~cm}$, according to the manufacturer) were applied, with a 10-min break between them. An analog torque meter (Tohnichi BTG60CN, Tohnichi, Tokyo, Japan) was used to achieve maximum preload. After $2 \mathrm{~min}$ of the second torque, the value of detorque was measured and recorded according to the methodology proposed by Khraisat et al. in 2004. ${ }^{[13]}$ The samples underwent cyclic mechanical testing (Instron 8801, Instron, Grove City, PA, USA), whereby $400 \mathrm{~N}$ of axial force was applied over a crown surface at a frequency of $8 \mathrm{~Hz}$ for a total of 1 million cycles; this process simulated a year of implant function. ${ }^{[10]}$ After the fatigue test, the samples were set on the torque meter to measure and record the final detorque value as previously described.

The averages were calculated and statistically analyzed by two-way analysis of variance (ANOVA) and Tukey's test at a 5\% significance level. The initial and final detorque values and the intra- and inter-group differences between these values were assessed.

\section{RESULTS}

Table 1 shows the data of the average initial detorque (T0) and final detorque (T1) values $(\mathrm{N} \mathrm{cm})$, with $\alpha=0.05$. 
Feitosa, et al.: Stability of implant connections after a fatigue test

\begin{tabular}{|c|c|c|}
\hline Group & TO & T1 \\
\hline $\mathrm{EH}$ & $12.80 \pm 2.86 \mathrm{~B}, \mathrm{a}$ & $10.40 \pm 0.55 \mathrm{C}, \mathrm{a}$ \\
\hline $\mathrm{IH}$ & $15.40 \pm 2.07 \mathrm{AB}, \mathrm{a}$ & $13.80 \pm 1.30 \mathrm{~B}, \mathrm{a}$ \\
\hline MT & $18.60 \pm 0.89 \mathrm{~A}, \mathrm{a}$ & $19.40 \pm 0.55 \mathrm{~A}, \mathrm{a}$ \\
\hline
\end{tabular}

There was no statistically significant difference between the values of $\mathrm{T} 0$ and $\mathrm{T} 1$ of the intra-group samples. However, a statistically significant difference in T0 was found between the EH and MT groups $(P=0.012)$. The MT group obtained higher T0 values than the $\mathrm{EH}$ group, and the IH group obtained intermediate values of T0 without statistical difference. The T1 means showed that the MT group obtained the highest values followed by the IH and EH groups, which had the lowest values of T1 $(P=0.001)$.

\section{DISCUSSION}

The implant/abutment interface has been reported to be the primary factor in stress distribution, adverse biological responses, and other prosthetic complications. ${ }^{[3,4]}$ Therefore, torque plays an important roleinmaintaining the integrity of theimplant/abutment interface, as it reduces the tendency of screw loosening and margin opening when it is correctly applied with accuracy and proper technique. In a recently published systematic review on implant-related complications, Jung et al. ${ }^{[14]}$ calculated the cumulative incidence of connection-related complications (screw loosening, $12.7 \%$ and fracture, $0.35 \%$ ) in 5 years of clinical service. Gokcen-Rohlig et al. ${ }^{[15]}$ found similar results.

Despite the widespread use of external hexagon connections, ${ }^{[3,11,16]}$ failure rates ranging from 6 to $48 \%$ have been described in the medical literature. A lower stability of external connections was found when the results of this study were analyzed. The initial detorque (T0) and final detorque (T1) values found in the EH group were statistically lower than those measured in the MT group and IH group when considering the values shown in T1; these results are in agreement with other studies. ${ }^{[11,17]}$

This greater stability of the internal connections, especially the Morse taper, is important because it provides more predictable rehabilitation with greater longevity and success rates. This connection provides higher resistance at the implant/abutment interface, anti-rotational characteristics, and resistance to loosening of the screw. ${ }^{[1,16-19]}$ Both the internal hexagon connection and the Morse taper had higher final detorque values (T1) when compared with the values of the external hexagon connection, although the difference between the values of the initial detorque (T0) of the external and internal hexagon were not statistically significant. Compared with the internal hexagon connection, torque loss was not obtained in the Morse taper connection after cyclic testing, and the difference was statistically significant. Squier et al. in $2002^{[20]}$ stated that abutments of the Morse taper connection showed detorque values higher than the initial torque due to the cold solder on the implant/abutment interface agreement with the results of this study. This condition arises from the friction between the two surfaces, which differ slightly; the pressure created by the insertion force determines the maintenance of the connection even after stopping the applied force for insertion.

Another factor of great importance for the stability of the connection is the screw. Its shape, size, and coating material, as well as the compressive force it exerts, known as preload, are crucial to maintaining stability of the connection; this has already been studied extensively. ${ }^{[20-22]}$ The material of the screw is the most significant factor in determining the characteristics of its union. ${ }^{[3]}$ The threads of the titanium screw, in contact with the threads of the implant, promote a connection that results from the sliding contact between the inner surfaces of the same material. This form of contact results in a greater coefficient of friction. Gold screws have a low coefficient of friction, which allows higher torque values without the threads adhering to the titanium threads of the implant. In an attempt to reduce the coefficient of friction, manufacturers surface treat the screws. In 2001, Martin et al. ${ }^{[23]}$ investigated the generation of preload in four brands of screws and concluded that surface treatment of bolts reduced the coefficient of friction, resulting in higher preload values. Factors that influence preload are the geometry of the screw (thread pitch) and the mechanical properties of metal, including texture, surface finishing, surface settlement, and degree of lubrication. ${ }^{[5,9,16,24-27]}$

The screws used in this study had the same characteristics for all groups, so the difference was the contact surface and the interaction between the screw and the internal surface of the implant due to differences in implant geometries (external, internal, and Morse). The results obtained in this study agree with those of other studies in the literature ${ }^{[11,28]}$ which show that internal connections are more stable mechanically than external flat connections. The general focus is clearly 
on deep internal connections in which the screw takes little or no load and provides intimate contact with the implant walls to resist micromovement.

Important issues to be addressed are the amount of torque to be applied and the device used. The literature states that the maximum torque should not exceed $75 \%$ of the maximum strength of the bolts and that the torque recommended by the manufacturer varies with the type, configuration, and diameter of the device. ${ }^{[25]}$ The device used to apply the torque in this study had an accuracy of about $98 \%$.

Fatigue tests allow simulation of clinical function. However, published studies have used different methodologies for the applied axial load, frequency, and number of cycles. ${ }^{[5,26,27]}$ The frequency of cycles is reported in the literature as ranging from 1 to $19 \mathrm{~Hz} \cdot{ }^{[27]}$ It was clarified that in a day, an individual typically performs three episodes of chewing lasting $15 \mathrm{~min}$, with a frequency of 60 cycles per minute $(1 \mathrm{~Hz})$; this generates 2700 chewing cycles per day, which equals 1 million cycles per annum. ${ }^{[26]}$ Considering that the frequency appears to have little importance in fatigue studies, the methodology uses a frequency of $8 \mathrm{~Hz} \cdot{ }^{[10]}$ The reported incident forces in molars ranged from 390 to $880 \mathrm{~N}$, in premolars was $453 \mathrm{~N}$, and in incisors was $222 \mathrm{~N}$. Thus, a load of $400 \mathrm{~N}$ was used in the region of the premolar. ${ }^{[6,10]}$

The results obtained after the fatigue test showed a decrease of torque in samples of the different groups. The decrease of torque was more evident in the external hexagonal connections followed by the internal hexagon connections; the best result was found in the Morse taper connections, which indicates that the initial hypothesis is true.

Finally, although laboratory studies have limitations that should be considered when compared with the clinical reality, these studies are important as they contribute to the advancement of dentistry. In this study, different internal geometries of dental implants were investigated; however, the abutments and screws used were of the same materials and geometry. Thus, future studies comparing different geometries and materials of abutment and screw should be performed, and also, mechanical fatigue testing with a higher number of cycles should be done.

\section{CONCLUSION}

Considering the limitations of this laboratory experiment, the results showed the following: In case of single restorations, the internal connections were more stable than external connections, and the Morse taper connection showed a better stability than the internal hexagon and external hexagon connections after mechanical cycling.

\section{CLINICAL CONCLUSION}

When properly indicated, the Morse taper connection may exhibit improved stability of the prosthesis even after mechanical stress.

\section{REFERENCES}

1. Kim SK, Lee JB, Koak JY, Heo SJ, Lee KR, Cho LR, et al. An abutment screw loosening study of a diamond like carbon-coated CP titanium implant. J Oral Rehabil 2005;32:346-50.

2. Davi LR, Golin AL, Berbardes SR, Araújo CA. Neves FD. In vitro integrity of implant external hexagon after application of surgical placement torque simulating implant locking. Braz Oral Res 2008;22:125-31.

3. Binon PP. Implants and components: Entering the new millennium. Int J Oral Maxillofac Implants 2000;15:76-91.

4. Ricomini Filho AP, Fernandes FS, Straioto FG, da Silva WJ, Del Bel Cury AA. Preload loss and bacterial penetration on different implant-abutment connection systems. Braz Dent J 2010;21:123-9.

5. Cibirka RM, Nelson SK, Lang BR, Rueggeberg FA. Examination of implant abutment interface after fatigue testing. J Prosthet Dent 2001;85:268-75.

6. Assunção WG, Barão VA, Delben JA, Gomes ÉA, Garcia IR Jr. Effect of unilateral misfit on preload of retention screws of implant-supported prostheses submitted to mechanical cycling. J Prosthodont Res 2011;55:12-8.

7. Kano SC, Binon PP, Curtis DA. A classification system to measure the implant-abutment microgap. Int J Oral Maxillofac Implants 2007;22:879-85.

8. Barbosa GA, Bernardes SR, das Neves FD, Fernandes Neto AJ, de Mattos $\mathrm{M}$ da G, Ribeiro RF. Relation between Implant/Abutment Vertical Misfit and Torque Loss of Abutment Screws. Braz Dent J 2008;19:358-63.

9. Hoyer SA, Stanford CM, Buranadham S, Fridrich T, Wagner J, Gratton D. Dynamic fatigue properties of the dental implant-abutment interface: Joint opening in wide-diameter versus standard-diameter hex-type implants. J Prosthet Dent 2001;85:599-607.

10. Lee CK, Karl M, Kelly JR. Evaluation of test protocol variables for dental implant fatigue research. Dent Mater 2009;25:1419-25.

11. Maeda Y, Satoh T, Sogo M. In vitro differences of stress concentrations for internal and external hex implant-abutment connections: A short communication. J Oral Rehabil 2006;33:75-8.

12. Wahl C, França FM, Brito RB Jr, Basting RT, Smanio H. Assessment of the tensile strength of hexagonal abutments using different cementing agents. Braz Oral Res 2008;22:299-304.

13. Khraisat A, Hashimoto A, Nomura S, Miyakawa O. Effect of lateral cyclic loading on abutment screw loosening of an external hexagon implant system. J Prosthet Dent 2004;91:326-34.

14. Jung RE, Pjetursson BE, Glauser R, Zembic A, Zwahlen M, Lang NP. A systematic review of the 5-year survival and complication rates of implant-supported single crowns. Clin Oral Implants Res 2008;19:119-30.

15. Gokcen-Rohlig B, Yaltirik M, Ozer S, Tuncer ED, Evlioglu G. Survival and Success of ITI Implants and Prostheses: Retrospective Study of Cases with 5-Year Follow-Up. Eur J Dent 2009;3:42-9.

16. Tabata LF, Rocha EP, Barão VA, Assunção WG. Platform switching: Biomechanical evaluation using three-dimensional finite element analysis. Int J Oral Maxillofac Implants 2011;26:482-91.

17. Park JK, Choi JU, Jeon YC, Choi KS, Jeong CM. Effects of abutment screw coating on implant preload. J Prosthodont 2010;19:458-64.

18. Mangano C, Bartolucci EG. Single tooth replacement by morse taper connection implants: A retrospective study of 80 implants. Int J Oral Maxillofac Implants 2001;16:675-80. 
Feitosa, et al: Stability of implant connections after a fatigue test

19. Krennmair G, Schmidinger S, Waldenberger O. Single-tooth replacement with the Frialit-2 system: A retrospective clinical analysis of 146 implants. Int J Oral Maxillofac Implants 2002;17:78-85.

20. Squier RS, Psoter WJ, Taylor TD. Removal torques of conical, tapered implant abutments: The effects of anodization and reduction of surface area. Int J Oral Maxillofac Implants 2002;17:24-7.

21. Weiss EI, Kozak D, Gross MD. Effect of repeated closure on opening torque value in seven abutment-implant systems. J Prosthet Dent 2000;84:194-9.

22. Tan KB, Nicholls JI. Implant-abutment screw joint preload of 7 hex-top abutment systems. Int J Oral Maxillofac Implants 2001;16:367-77.

23. Martin WC, Woody RD, Miller BH, Miller AW. Implant abutment screw rotations and preloads for four different screw materials and surfaces. J Prosthet Dent 2001;86:24-32.

24. Aboyoussef H, Weiner S, Ehrenberg D. Effect as an antirotation resistance form on screw loosening for single implant-supported crowns. J Prosthet Dent 2000;83:450-5.

25. Nigro F, Sendyk CL, Francischone CE Jr, Francischone CE. Removal torque of zirconia abutment screws under dry and wet conditions. Braz Dent J 2010;21:225-8.
26. Gratton DG, Aquilino SA, Stanford CM. Micromotion and dynamic fatigue properties of the dental implant-abutment interface. J Prosthet Dent 2001;85:47-52.

27. Lee J, Kim YS, Kim CW, Han JS. Wave analysis of implant screw loosening using an air cylindrical cyclic loading device. J Prosthet Dent 2002;88:402-8.

28. Norton MR. An in vitro evaluation of the strength of an internal conical interface compared to a butt joint interface in implant design. Clin Oral Implants Res 1997;8:290-8.

\begin{tabular}{|l|l|}
\hline \multicolumn{2}{|c|}{ Access this article online } \\
\hline Quick Response Code: & Website: \\
\hline & www.eurjdent.com \\
\hline & \\
\hline
\end{tabular}

\section{“QUICK RESPONSE CODE” LINK FOR FULL TEXT ARTICLES}

The journal issue has a unique new feature for reaching to the journal's website without typing a single letter. Each article on its first page has a "Quick Response Code". Using any mobile or other hand-held device with camera and GPRS/other internet source, one can reach to the full text of that particular article on the journal's website. Start a QR-code reading software (see list of free applications from http://tinyurl.com/yzlh2tc) and point the camera to the QR-code printed in the journal. It will automatically take you to the HTML full text of that article. One can also use a desktop or laptop with web camera for similar functionality. See http://tinyurl.com/2bw7fn3 or http://tinyurl.com/3ysr3me for the free applications. 